\title{
Graves's Ophthalmopathy and Covid19: Choices and Cautions
}

\author{
Ramin Kheirjou ${ }^{1 *}$ and Sahar Soltani ${ }^{2}$ \\ ${ }^{1}$ Departament of Medicine, Tehran University of Medical Sciences, Iran \\ ${ }^{2}$ Department of Medicine, Zanjan University of Medical Sciences, Iran
}

Submission: March 06, 2021; Published: May 13, 2021

*Corresponding author: Ramin Kheirjou, Tehran University of Medical sciences, Enqelab Square, Tehran, Iran

\begin{abstract}
Graves is a common autoimmune disease of the thyroid which results in many complications especially ophthalmopathy. Graves's ophthalmopathy is an inflammatory process that results in the enlargement of orbital soft tissues and vision problems. There are different approaches offered to the treatment of this problem. Recently the world has faced with covid 19 outbreak crises which can influence other disease and their treatment plans. We performed a review to determine the management of Graves's ophthalmopathy in regards to the SARSCoV-2 pandemic. We concluded despite common reports of thyroid dysfunction in covid 19 diseases; it is not associated with an increased risk of COVID-19 related hospitalization or a worse outcome. We also recommend orbital radiotherapy and corticosteroid plus selenium supplement as the best choice for Graves ophthalmopathy.
\end{abstract}

Keywords: Covid 19; Graves; Ophthalmopathy

\section{Introduction}

Coronavirus disease 2019 (COVID-19), caused by severe acute respiratory syndrome coronavirus 2 , has developed into a global pandemic. The mean rate of mortality has been reported to be nearly $14.4 \%$ which is higher in patients with underlying diseases [1]. Graves is a common autoimmune disease of the thyroid which results in many complications especially ophthalmopathy. Graves's ophthalmopathy is an inflammatory process that results in enlargement of orbital soft tissues and extraocular muscles which lead to eyelid retraction and proptosis and also vision problems [2]. According to the pathophysiological features of the thyroid dysfunction with regards to SARS-CoV-2 infection, the current Review discusses the management of graves ophthalmopathy during the covid 19 pandemic.

\section{Discussion}

Angiotensin-converting enzyme 2 used by covid 19 virus as a cellular entry receptor. Some endocrine glands like the thyroid do express ACE2 [3]. It has been established that follicular cells were injured in SARS-infected patients. Evidence of the presence of viruses or their components in the thyroid are established for some other viruses so could be one of mechanism leads to low serum triiodothyronine and thyroxine levels in patients with covid 19 infection, however it is not clarified that are these viruses responsible for thyroid diseases or just inactive components $[4,5]$. A study conducted during the SARS outbreak in 2003 and also recent study in 2019 showed that serum T3 and T4 levels were lower in patients with SARS and covid 19 and this decrease linked with severity of the infection [6,7]. There are some studies which reported covid 19 related subacute thyroiditis too $[8,9]$.

Thyroid hormones could increase the antiviral action of IFN- $\gamma$ and the immune system dysfunction duo to hypothyroidism may increase infection risk despite pathophysiological documents which show high probable infection risk in thyroid dysfunction, hypothyroidism is not associated with increased risk of COVID-19 related hospitalization or a worse outcome so far, Coronavirus disease 2019 [COVID-19] involved the respiratory system regularly, also complicated by viremia and SIRS [10-14]. The hyperinflammatory state associated with severe covid 19 diseases could have triggered an immunological reaction which leads to graves exacerbation and related problem includes ophthalmopathy [15]. The progression of Graves's ophthalmopathy varies among different patients. Males and smokers are associated to severe disease [16].

Selenium may modulate immune system and according to some studies and theoretically could help graves ophthalmopathy improvement. Furthermore, it has a potential effect on the 
prevention of covid 19 [17]. In 50_200 $\mu \mathrm{g}$ /day dosage no side effects were reported [18]. Chloroquine is another treatment that showed efficacy in the control of adipogenesis and hyaluronan production in graves ophthalmopathy by inhibiting autophagy mechanism These features plus its antiviral activity could make it selective for treatment but unfortunately, it has serious adverse ophthalmic reactions like extraocular muscle palsy, anterior uveitis, and optical neuritis which are more frequent in high cumulative dose [19-21]. Patients with graves that use antithyroid drugs are at risk of agranulocytosis that is more likely to occur in the initiation of treatment.

Agranulocytosis could lead to severe infections and is more necessary to inform the patient about alarm signs follow them accurately especially in the covid 19 pandemic [22]. Orbital radiotherapy and corticosteroids both available and effective treatment in graves ophthalmopathy however Combination of them results in better outcomes [23], but corticosteroid decreases immune system response which is linked to a high risk of viral disease and some studies advice corticosteroid should be postponed in covid 19 time Surgery as an alternative approach and after the failure of first-line treatment or in severe situations like compressive optic neuropathy should be implemented [24,25].

\section{Conclusion}

Combination of corticosteroid and orbital radiotherapy plus selenium supplement and stop smoking is recommended for graves ophthalmopathy during covid 19 pandemic in this review. Physicians need to be extra attentive in the management of thyroid dysfunction due to their effects on immunity.

\section{References}

1. Alshukry A, Ali H, Ali Y, Al-Taweel T, Abu-Farha, et al. (2020) Clinical characteristics of Coronavirus Disease 2019 (COVID-19) patients in Kuwait. PloS one 15(11): e0242768.

2. Hodgson NM, Rajaii F (2020) Current understanding of the progression and management of thyroid associated orbitopathy: A systematic review. Ophthalmol Ther 9(1): 21-33.

3. Pal R, Banerjee M (2020) COVID-19 and the endocrine system: exploring the unexplored. J Endocrinol Invest 43(7): 1027-1031.

4. Wei L, Sun X, Kanbe K, Wang Z, Sun C, et al. (2006) Chondrocyte death induced by pathological concentration of chemokine stromal cellderived factor-1. J Rheumatol 33(9): 1818-1826.

5. Desailloud R, Hober D (2009) Viruses and thyroiditis: an update. Virol J 6(1): 1-14

6. Wang W, Ye YX, Yao H, Sun LQ, Wang AS, et.al (2003) Evaluation and observation of serum thyroid hormone and parathyroid hormone in patients with severe acute respiratory syndrome. J Chin Antituberculous Assoc 25: 232-234.

7. Chen M, Zhou W, Xu W (2021) Thyroid function analysis in 50 patients with COVID-19: a retrospective study. Thyroid 31(1): 8-11.

8. Mehta OP, Bhandari P, Raut A, Kacimi SEO, Huy NT (2021) Coronavirus
Disease (COVID-19): Comprehensive Review of Clinical Presentation. Front Public health 8: 1034

9. Brancatella A, Ricci D, Viola N, Sgrò D, Santini F, et al. (2020) Subacute thyroiditis after SARS-CoV-2 infection. J Clin Endocrinol Metab 105(7): 2367-2370.

10. De Vito P, Incerpi S, Pedersen JZ, Luly P, Davis F B, et al. (2011) Thyroid hormones as modulators of immune activities at the cellular level. Thyroid 21(8): 879-890.

11. Guan WJ, Liang WH, Zhao Y, Liang HR, Chen ZS, Li et.al. (2020). Comorbidity and its impact on 1590 patients with COVID-19 in China: a nationwide analysis. European Respiratory Journal, 55(5)

12. van Gerwen M, Alsen M, Little C, Barlow J, Naymagon L, et.al. (2020). Outcomes of Patients with hypothyroidism and COVID-19: a retrospective cohort study. Frontiers in endocrinology 11: 565.

13. John M, Veetil VM (2020) Management of thyroid diseases during pandemic: A narrative review. Thyroid Research and Practice 17(2): 62.

14. Wilson JG, Simpson LJ, Ferreira AM, Rustagi A, Roque J, et al. (2020). Cytokine profile in plasma of severe COVID-19 does not differ from ARDS and sepsis. JCI insight 5(17).

15. Jiménez-Blanco S, Pla-Peris B, Marazuela M (2021) COVID-19: a cause of recurrent Graves' hyperthyroidism?. Journal of Endocrinological Investigation 44(2): 387-388.

16. Nabi T, Rafiq N (2020) Factors associated with severity of orbitopathy in patients with Graves' disease. Taiwan Journal of Ophthalmology, $10(3), 197$.

17. Sahin E, Orhan C, Uckun FM, Sahin K (2020) Clinical Impact Potential of Supplemental Nutrients as Adjuncts of Therapy in High-Risk COVID-19 for Obese Patients. Frontiers in nutrition 7.

18. Bednarczuk T, Schomburg L (2020) Challenges and perspectives of selenium supplementation in Graves' disease and orbitopathy. Hormones 19(1): 31-39.

19. Guo Y, Li H, Chen X, Yang H, Guan H, et.al. (2020). Novel roles of chloroquine and hydroxychloroquine in Graves' orbitopathy therapy by targeting orbital fibroblasts. The Journal of Clinical Endocrinology \& Metabolism 105(6): 1906-1917.

20. Noureddine O, Issaoui N, Al-Dossary O (2021) DFT and molecular docking study of chloroquine derivatives as antiviral to coronavirus COVID-19. Journal of King Saud University-Science 33(1): 101248.

21. Lacava AC (2010) Ocular complications of chloroquine and derivatives therapy. Arquivos brasileiros de oftalmologia, 73(4): 384-389.

22. Kaiser UB, Mirmira RG, Stewart PM (2020) Our response to COVID-19 as endocrinologists and diabetologists.

23. Stiebel-Kalish H, Robenshtok E, Hasanreisoglu M, Ezrachi D, Shimon I, et al (2009) Treatment modalities for Graves' ophthalmopathy: systematic review and metaanalysis. The Journal of Clinical Endocrinology \& Metabolism 94(8): 2708-2716.

24. Kahaly GJ (2020) Management of Graves Thyroidal and Extrathyroidal Disease: An Update. The Journal of Clinical Endocrinology \& Metabolism, 105(12), 3704-3720.

25. Patel TR, Halsey JN (2020) Advances in the Orbital Decompressive Surgery for the Treatment of Graves' Ophthalmopathy. In Advances in Treatment and Management in Surgical Endocrinology (pp. 247-258). Elsevier. 

(C) (ن) $\begin{aligned} & \text { This work is licensed under Creative } \\ & \text { Commons Attribution 4.0 Licens }\end{aligned}$ DOI: 10.19080/JETR.2021.06.555678

- Swift Peer Review

- Reprints availability

- E-prints Service

- Manuscript Podcast for convenient understanding

- Global attainment for your research

- Manuscript accessibility in different formats

( Pdf, E-pub, Full Text, Audio)

- Unceasing customer service

Track the below URL for one-step submission https://juniperpublishers.com/online-submission.php 